\title{
Significados de Internet para el ejercicio profesional: una aproximación desde el diseño gráfico
}

\author{
Meanings of the Internet in professional practice: an approach from graphic \\ design
}

Significados da Internet para a prática profissional: uma abordagem do design gráfico

Edgar Oswaldo González Bello Universidad de Sonora, México edgar.gonzalezb@gmail.com http://orcid.org/0000-0001-6297-2516

Arodi Morales Holguín Universidad de Sonora, México

redeshmo@gmail.com https://orcid.org/0000-0001-9241-032X

\section{Resumen}

El objetivo de esta investigación fue conocer las percepciones de estudiantes y egresados de la licenciatura en Diseño Gráfico de la Universidad de Sonora acerca de la vinculación entre la Internet y su profesión. Para ello, se aplicó una entrevista, la cual estuvo constituida por ocho preguntas relacionadas con las siguientes dimensiones: influencia y posibilidades de la Internet, así como dependencia de la Internet en el ejercicio del diseño gráfico. Los datos obtenidos fueron analizados en el programa Atlas ti., por medio de la técnica de saturación. De forma general, se puede concluir que los estudiantes de la referida licenciatura sobrestiman el valor de la Web para desarrollar sus procesos creativos, mientras que los egresados asumen una posición más crítica con respecto al uso de dicho recurso, pues no lo consideran como una pieza clave para la creatividad o para lograr la calidad de un diseño. Aun así, ambos grupos de entrevistados coindicen en señalar que el diseño gráfico ha conseguido grandes avances gracias a la Internet; prueba de esto ha sido el surgimiento de 


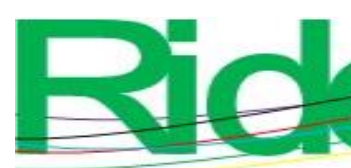

Revista Iberoamericana para la

Investigación y el Desarrollo Educativo

ISSN $2007-7467$

nuevos canales de comunicación, plataformas y dispositivos digitales desde los cuales es posible intercambiar ideas con usuarios de cualquier latitud. Por tal motivo, se recomienda al profesor de esta carrera mantenerse actualizado no solo en cuanto a sus conocimientos teóricos, sino también en lo referente a sus estrategias de enseñanza, las cuales se deben sustentar, ineludiblemente, en tecnologías vanguardistas que estimulen la creatividad. En esta tarea, lógicamente, las instituciones universitarias también tienen un compromiso trascendental, porque deberán promover el desarrollo profesional de los docentes, estableciendo y siguiendo programas de capacitación según las necesidades del mercado laboral y las tendencias globales.

Palabras clave: diseño gráfico, ejercicio profesional, formación, Internet, tecnología.

\section{Abstract}

The objective of this research was to know the perceptions of students and graduates of the degree in Graphic Design of the University of Sonora about the link between the Internet and their profession. For this, an interview was applied, which was constituted by eight questions related to the following dimensions: influence and possibilities of the Internet, as well as dependence on the Internet in the exercise of graphic design. The data obtained were analyzed in the Atlas ti program, by means of the saturation technique. In general, it can be concluded that the students of the aforementioned degree overestimate the value of the Web to develop their creative processes, while the graduates assume a more critical position regarding the use of said resource, since they do not consider it as a piece key to creativity or to achieve the quality of a design. Even so, both groups of interviewees co-point in pointing out that graphic design has made great progress thanks to the Internet; Proof of this has been the emergence of new communication channels, platforms and digital devices from which it is possible to exchange ideas with users of any latitude. For this reason, the professor of this career is recommended to keep updated not only in terms of his theoretical knowledge, but also in relation to his teaching strategies, which must be based, inevitably, on avant-garde technologies that stimulate creativity. Logically, in this task, university institutions also have a transcendental commitment, because they must promote the professional development of teachers, establishing and following training programs according to the needs of the labor market and global trends.

Keywords: graphic design, professional practice, training, Internet, Technology. 


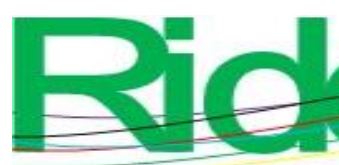

Revista Iberoamericana para la

Investigación y el Desarrollo Educativo

ISSN $2007-7467$

\section{Resumo}

O objetivo desta pesquisa foi conhecer as percepções de estudantes e egressos do curso de Design Gráfico da Universidade de Sonora sobre o vínculo entre a Internet e sua profissão. Para isso, foi aplicada uma entrevista, constituída por oito questões relacionadas às seguintes dimensões: influência e possibilidades da Internet, bem como dependência da Internet no exercício do design gráfico. Os dados obtidos foram analisados no programa Atlas ti, por meio da técnica de saturação. De maneira geral, pode-se concluir que os alunos do referido diploma superestimam o valor da Web para desenvolver seus processos criativos, enquanto os egressos assumem uma posição mais crítica em relação ao uso do referido recurso, uma vez que não o consideram como uma peça. chave para a criatividade ou para alcançar a qualidade de um design. Mesmo assim, ambos os grupos de entrevistados apontam que o design gráfico fez grandes progressos graças à Internet; Prova disso tem sido o surgimento de novos canais de comunicação, plataformas e dispositivos digitais a partir dos quais é possível trocar idéias com usuários de qualquer latitude. Por essa razão, recomenda-se ao professor desta carreira manter-se atualizado não só em termos de seu conhecimento teórico, mas também em relação às suas estratégias de ensino, que devem se basear, inevitavelmente, em tecnologias de vanguarda que estimulem a criatividade. Logicamente, nessa tarefa, as instituições universitárias também têm um compromisso transcendental, pois devem promover o desenvolvimento profissional dos professores, estabelecendo e acompanhando os programas de treinamento de acordo com as necessidades do mercado de trabalho e as tendências globais.

Palavras-chave: design gráfico, prática profissional, treinamento, Internet, tecnologia.

Fecha Recepción: Abril 2019

Fecha Aceptación: Agosto 2019

\section{Introducción}

Internet es una de las invenciones humanas que más efectos ha tenido no solo para el desarrollo de las múltiples actividades diarias, sino también para el ejercicio de las diversas profesiones, entre las que se destaca el diseño gráfico. Esto ha sucedido gracias a los distintos avances tecnológicos que han contribuido a optimizar los flujos de navegación y transferencia de datos, lo cual ha generado innumerables trasformaciones en la manera en que se crea y se gestiona la información (Brunner, 2003). Esto, lógicamente, ha obligado a las profesiones y a las instituciones educativas (entre las que se destacan las universidades) a desarrollar en los 


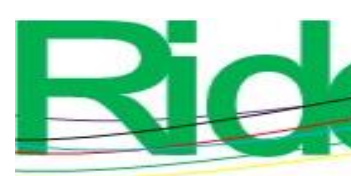

Revista Iberoamericana para la

Investigación y el Desarrollo Educativo

ISSN $2007-7467$

estudiantes nuevas capacidades creativas e innovadoras para adaptarse de la mejor manera posible a las exigencias laborales de un mundo cada vez más cambiante (Puddephatt, 2016).

En el caso específico de la profesión de diseño gráfico, Jódar (2010) y Carpio (2016) señalan que en esta especialidad se requieren habilidades que les permitan a los profesionales explotar los innumerables beneficios que ofrecen la Internet y los dispositivos digitales para conectarse e interactuar de forma más versátil. Es cierto que en décadas pasadas el diseño era dominado por expresiones de tipo artísticas, las cuales podían ser interpretadas como ventanas que permitían entender la realidad de cada momento histórico.

Sin embargo, con el surgimiento del consumismo, la industrialización, la mercadotecnia y los medios de comunicación digital, el diseño gráfico empezó a cumplir una función más comercial como herramienta de comunicación para el servicio de la empresa moderna. Esto, por supuesto, también creó no solo nuevos desafíos (los cuales se evidencian de forma particular en los elementos de naturaleza tipográfica como el color), sino también espacios de trabajo impensados en otras épocas.

En efecto, tradicionalmente el diseño gráfico se había manifestado de forma preponderante en las calles, las revistas, la televisión, entre otros. No obstante, el surgimiento de la tecnología digital impulsó una evolución en cuanto a las posibilidades de materializar este campo disciplinar. Una muestra de ello ha sido la Internet, espacio digital que llevó a los espectadores de aquellos canales tradicionales a una realidad virtual donde los múltiples dispositivos electrónicos (como el teléfono inteligente) se han convertido en la ventana favorita para interactuar con el mundo. Se trata de un escenario donde la tecnología y la Web se conjugan para brindar a los diseñadores gráficos la oportunidad de ser testigos de un despliegue de posibilidades usualmente ilimitadas, las cuales sirven para desplazarse en un entorno donde prácticamente todo está disponible.

Todo lo anterior, sin embargo, se debe asumir en medio de una serie compleja de exigencias, las cuales se relacionan con la habilidad para manejar de forma estética las expresiones interactivas y los elementos visuales para permitir que determinada composición pueda ser leída y comprendida con el mínimo de cansancio (Sánchez, 2009). Estos son concebidos como problemas de comunicación, de inteligibilidad, de información y de estructura, a los cuales el diseñador se debe enfrentar cuando ejerce su profesión. 


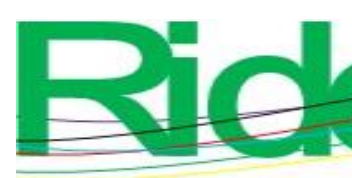

Revista Iberoamericana para la

Investigación y el Desarrollo Educativo

ISSN $2007-7467$

Aunado a esto —y según Carpio (2016)—, el diseñador gráfico depende de tecnologías como la Internet que afectan no solo en la producción y distribución de los mensajes, sino también en los otros medios de la comunicación que intervienen en los procesos creativos, los cuales posibilitan la generación de nuevos objetos comunicacionales. En ese sentido, la expansión de la Internet y su acceso a través de dispositivos móviles ha generado otras maneras de dirigirse y de impactar en el observador, lo que ha obligado a los diseñadores a mantener una actualización constante para procurar satisfacer las demandas de los usuarios de este medio virtual.

Además, con la aparición de las redes sociales, el diseñador gráfico también debe trabajar en la orientación y el enfoque que plantean los diferentes perfiles de usuarios de Internet. En este sentido, el campo de acción del diseñador y las formas de comunicación a través de la Internet cobran más fuerza debido a que las tecnologías se constituyen como un factor inherente a esta profesión (Castells, 2009).

En síntesis, Internet ha hecho posible la comunicación interactiva y el desarrollo de nuevos productos multimedia que las universidades, en general, y los profesores, en particular, deben tomar en cuenta en sus programas de formación (Husted, Álvarez, Rodríguez, Rodríguez y Mancillas, 2016) para que los futuros profesionales puedan cumplir con las expectativas que reclama el mercado laboral (Brunner, 2003).

\section{El diseño gráfico en tiempos de Internet}

En muchas ocasiones se suele considerar a esta como una profesión simple. Sin embargo, también se debe prever — como lo explica Rand (1965)— que todo es diseño, pues los objetos y las imágenes creadas por el hombre han sido el resultado de un proceso planificado que persigue algún fin en específico. En palabras de Guerrero, Hernandis y Agudo (2018), "el diseño es una actividad en la que se definen los aspectos formales y la apariencia del producto" (p. 26), de modo que los atributos funcionales en el diseño determinan en gran medida las necesidades, los objetivos y la materialización de lo que se quiere conseguir.

Conocida con el nombre diseño gráfico, esta labor tiene su historia y con el tiempo se ha venido especializando atendiendo las necesidades particulares de su entorno (Meggs, 2000). De hecho, desde su concepción como disciplina, se ha entendido como una actividad 


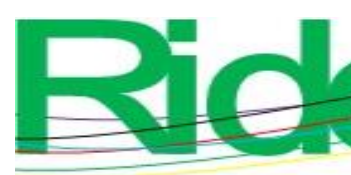

Revista Iberoamericana para la

Investigación y el Desarrollo Educativo

ISSN $2007-7467$

preponderantemente práctica y dominada por un perfil artístico. Pero luego, como lo indican Morales y Cabrera (2017), las condiciones del ambiente comercial del siglo XX impulsaron su profesionalización debido al crecimiento del mercado, el repunte de la actividad económica global y la competitividad existente. Este fue el escenario propicio para que el diseño gráfico estimulara al auge de las marcas, lo cual sucedió gracias a la aparición de las primeras computadoras.

Efectivamente, un acontecimiento relevante para el diseño gráfico fue la aparición de la Macintosh de Apple en 1984 (primera computadora personal comercializada exitosamente) porque con ella el diseño gráfico pudo transitar hacia una nueva dimensión que le permitió redefinir su realidad e ingresar a la era de la información, aunque conviviendo todavía con técnicas tradicionales como la serigrafía, la ilustración y la fotografía (Meggs, 2000).

En décadas más recientes, sin embargo, se experimentaría una gran transición que llevó a los diseñadores a sustituir muchas de las técnicas que habían venido utilizando durante décadas por otras que se apoyaban en la computadora y en la Internet. Según Costa (2014), en ese momento quedó atrás el industrialismo y surgió el posindustrialismo, es decir, una nueva realidad donde predominaba la economía de la información y la cultura de servicio. De este modo surgiría una cultura de lo inmaterial, de los intangibles y de los valores que trasformarían la existencia, así como la forma de ver, pensar y entender el mundo de una manera más intensa y rápida, a diferencia de otras épocas donde la Internet era inimaginable.

En la actualidad, el diseño gráfico es concebido como una forma de comunicación desarrollada en el contexto visual, lo que ha generado un tejido sistémico y denso de naturaleza altamente compleja. En concordancia con esta idea, Frascara (2000) define el diseño gráfico como aquella "acción de concebir, programar y proyectar comunicaciones visuales producidas en general por medios industriales y destinados a transmitir mensajes específicos a grupos determinados" (p. 19). Este concepto describe la interrelación de una gran variedad de componentes heterogéneos y altamente integrados, donde la Internet y todas las tecnologías juegan un papel preponderante.

Por ello, para entender el diseño gráfico actual no basta con referirse al vasto contexto de la comunicación, pues también se deben incluir otros fenómenos tan amplios como la imagen digital $\mathrm{y}$, especialmente, la construcción comunicativo-visual discursiva, cuya fenomenología se interrelaciona de manera muy estrecha con el manejo emocional enfocado 


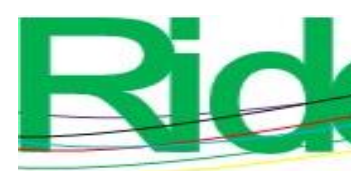

Revista Iberoamericana para la

Investigación y el Desarrollo Educativo

ISSN 2007 - 7467

en la persuasión. En este contexto, Velásquez y Paladines (2011) señalan que con la Internet se han podido vincular diversos recursos tecnológicos (como computadoras, teléfonos inteligentes y videojuegos), los cuales han abierto nuevos canales y oportunidades para impactar directamente en los procesos comunicativos.

No obstante, también vale recalcar la opinión de Barrientos (2017), quien advierte que si bien la vinculación entre el mundo digital y el diseño gráfico han trasformado la manera de ejercer esta profesión, existe una nueva realidad que está llevando a la sustitución de muchas actividades, de ahí que se vislumbre el surgimiento de un perfil profesional que se adapte a las nuevas demandas. Efectivamente, dado que el diseño en todas sus expresiones tiene como fin impulsar los negocios, resulta cada vez más relevante trabajar en la comunicación de la marca a través de la publicidad, la cual en la actualidad está cambiando sus medios y canales tradicionales por otros digitales. De este modo ha emergido el e-commerce, una de las principales manifestaciones del impacto de la Internet (Barrientos, 2017).

Este efecto de la tecnología — como lo apunta Ohmae (2005) — difícilmente pudo haber sido imaginado, aunque igualmente trasformó la manera de hacer publicidad, la cual se ha beneficiado con las facilidades que el mundo digital ofrece en la interacción visual del usuario con los distintos dispositivo (en especial, el teléfono inteligente) a través de interfaces y aplicaciones.

Igualmente, la tecnología ha reformado de manera sustancial los procesos de materialización del diseño gráfico, lo cual se evidencia en los mecanismos de impresión que no solo han reducido los costos y el tiempo invertido en la producción, sino que también han mejorado la calidad del trabajo. Para esto, por supuesto, se debe prever que los efectos que procura generar el diseño gráfico en los receptores no se producen por el simple uso de esta nueva tecnología, pues esta profesión no solo se enfoca en componer estéticamente un mensaje, sino que también procura generar percepciones e impulsar conductas particulares en el público para dotar de sentido a un producto-marca, idea o personaje.

Para esto, evidentemente, también se apoya en estrategias de comunicación visual (emisión y recepción de mensajes), de ahí que se le vincule con la publicidad. El trabajo del diseñador gráfico, en otras palabras, se enfoca en captar, entender y asimilar un código, el cual varía según las necesidades del emisor, así como las características y los deseos del receptor y el manejo de las distintas interpretaciones que pueden llegar a sufrir esos mensajes (Bernal, 2013). Desde la noción de Costa (2014), el diseño gráfico intenta establecer un 


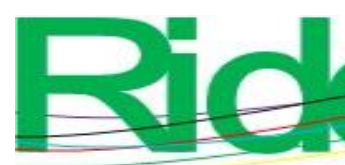

Revista Iberoamericana para la

Investigación y el Desarrollo Educativo

ISSN $2007-7467$

sistema de relaciones constantes entre las personas y los ambientes que ocupan, los objetos que se utilizan y los mensajes que integran. Así, los productos del diseño gráfico, en todas sus manifestaciones, forman parte de la cultura.

En síntesis, el escenario del diseño y de la comunicación visual de hoy en día difícilmente puede ser concebido fuera de los canales de comunicación que se han convertido en la herramienta interpersonal de la sociedad, denominada por Castells (2009) como sociedad de la información. Por eso, resulta difícil de imaginar la labor del diseñador sin el empleo de la tecnología y las redes digitales.

Expuesto todo lo anterior, y reconociendo este escenario particular — denominado por Brunner (2003) como contexto emergente-, en el presente documento se analizan las influencias y las posibilidades que brinda la Internet al diseño gráfico, así como otros aspectos que se han suscitado dentro del ejercicio del profesional que desempeña esta labor. Con esto se espera aportar conocimientos que permitan orientar el desarrollo de esta profesión y ofrecer alternativas para potenciar la formación que se ofrece en las universidades.

\section{Método}

En esta investigación se consideró el método cualitativo para analizar los significados generados por los 18 sujetos de estudio seleccionados (alumnos y egresados de la licenciatura en Diseño Gráfico de la Universidad de Sonora), a los cuales se les aplicó una entrevista en profundidad para conocer sus percepciones acerca de la vinculación entre la Internet y su profesión. En concreto, la guía de entrevista usada se enfocó en ocho preguntas relacionadas con las siguientes dimensiones: influencia y posibilidades de la Internet, así como dependencia de la Internet en el ejercicio del diseño gráfico. Para desarrollar este trabajo se partió de la premisa que sugiere que los significados se construyen a través de la interrelación de los sujetos (Marradi, Achenti y Piovani, 2010).

En cuanto a las características de los entrevistados, se puede decir que 7 fueron hombres y 11 mujeres, con edades que oscilaban entre los 21 y los 26 años. De ellos, 10 había egresado de la carrera hacía 1 o 3 años, mientras que los 8 restantes eran estudiantes de los últimos semestres. Todos afirmaron desempeñarse laboralmente en el campo del diseño gráfico. Los datos obtenidos fueron analizados en el programa Atlas ti., por medio de la 
técnica de saturación, la cual permitió reconocer diferentes hallazgos y aspectos interesantes que fueron identificados.

\section{Resultados y discusión}

Un diseñador gráfico busca convertirse en un profesional capaz de tener una visión estratégica y global de la comunicación y el diseño, con dominio de las competencias y las funciones propias de una dirección creativa para poder crear y dirigir proyectos en el campo de los mensajes visuales, audiovisuales y multimedia, con una visión del diseño en el conocimiento (Carpio, 2016). Lograr estas pretensiones depende para muchos del apoyo que obtengan de la Internet.

En cuanto a la competitividad en el campo del diseño gráfico, se puede afirmar que esta se ha incrementado debido a la expansión tecnológica, pues en otras épocas el comercio se limitaba principalmente a segmentos locales y regionales. Sin embargo, la aparición de la Internet trasformó el entorno laboral, con lo cual se convirtió en un nodo más de las redes globales (Castells, 2009). Esto ocasionó que en la estructura social se mezclara lo local y lo global al mismo tiempo, a diferencia de otras épocas donde estos espacios lograban diferenciarse de forma más sencilla (Held y Mcgrew, 2007).

A partir de la anterior idea, se puede decir que la influencia de la Internet en el diseño gráfico es percibida de forma positiva por entrevistados, los cuales buscan convertirse en ese "profesional” que demanda el campo laboral. Así lo demuestran los siguientes testimonios:

Internet le ha dado un impulso a la creatividad y ha otorgado herramientas que anteriormente eran imposibles de adquirir, por lo que el desarrollo es exponencial a años anteriores (entrevista 3, estudiante).

Genera un ambiente muy competitivo, pero muy rico en aprendizaje y entendimiento de tendencias y formas de realizar el diseño (entrevista 2, estudiante).

Internet me abre camino hacia nuevas perspectivas desde miles de mentes creativas y me da la oportunidad de nutrir mi capacidad visual; observar otros trabajos y compartiendo los míos, o leyendo artículos de experiencias laborales, por ejemplo (entrevista 12, egresado). 


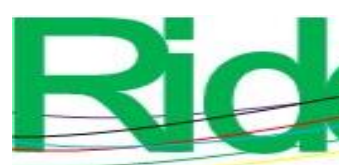

Revista Iberoamericana para la

Investigación y el Desarrollo Educativo

ISSN $2007-7467$

Ha facilitado muchos recursos visuales al igual que amplía nuestra perspectiva, complementando con ideas que tienen en otros lugares del mundo y así hacer un diseño más rico en contenido visual y funcional (entrevista 4, egresada).

En el campo del diseño gráfico, la creatividad es una de las cualidades que más deben ser desarrolladas. De hecho, según la opinión de los entrevistados, esta facultad se ha ido enriqueciendo y trasformado gracias al uso de la Internet. Por eso, se puede asegurar que dicho entorno virtual se ha convertido en un paradigma que ha dividido en un antes y en un después la historia del diseño, la cual, sin embargo, aún permanece unida por aportes de otros tiempos que se manifiestan en épocas más recientes, como la contribución que tuvo la heráldica medieval en la fenomenología del diseño. Tal ha sido esta influencia que todavía continúa presente en los estilos de signos gráficos de identidad - conocidos comúnmente como logotipos-, los cuales manifiestan una estética visual que se apoya en trazos geométricos, formas y color, así como en su carácter discursivo (Costa, 2004) presente en muchos productos del diseño actual.

Ahora bien, esta influencia del pasado en el presente sirve para demostrar que la creatividad es una cualidad inherente al ser humano, que se puede suscitar con o sin Internet. Por eso, sería arriesgado afirmar que este recurso digital ha sido el generador de la creatividad. En cambio, se podría considerar que la Web ha sido una herramienta que la ha favorecido porque facilita el acceso a una cantidad ilimitada de diseños, algo quizás inimaginable hasta hace unos años. A esto se suma el impacto que la Internet genera hacia el comercio global (Maciá, 2014), pues la tecnología y el diseño digital han dado a las empresas la flexibilidad no solo para interactuar con distintos tipos de clientes, sino también para llegar a otros potenciales alrededor del mundo.

Como ya se ha mencionado, gracias a la Internet la estructura social ha mezclado lo local y lo global al mismo tiempo, lo que ha permitido encontrar, convivir, aprender y proponer desde esos dos ámbitos. Así, los diseñadores han hallado una gran puerta que les ha permitido conocer el trabajo que se está desarrollando en otras latitudes. Pareciera que han quedado atrás - aunque no del todo - las épocas en que solo a través de los libros o de la televisión el diseñador se enteraba de las composiciones que se generaban en otros lugares. Tradicionalmente el diseñador gráfico tenía que esperar a que sus diseños fueran impresos o expuestos en algún medio para poder ser observados. 


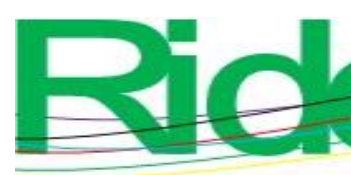

Revista Iberoamericana para la

Investigación y el Desarrollo Educativo

ISSN 2007 - 7467

En cambio, con la Internet ha surgido la oportunidad de acercar los productos no solo a los clientes habituales, sino también a cualquier observador en cualquier parte del mundo. Por eso, se puede decir que la Red ha posibilitado el acceso a nuevas perspectivas desde otras mentes creativas. Además, las nuevas propuestas son encontradas en este espacio virtual antes que en otra parte, con lo cual se nutre el imaginario visual creativo. En pocas palabras, Internet sí ha venido a ser una oportunidad para el diseñador y el diseño en todas sus expresiones.

A partir de esta reflexión se puede asumir que las posibilidades del ejercicio del diseño se ven influenciadas con el acceso a la Internet. Esto se debe a la apertura casi ilimitada que ofrece de los contenidos. Por ello, si se acepta aquella premisa de que todo es diseño, entonces resultan inimaginables las cantidades de recursos visuales que se pueden encontrar en esta nueva ventana del mundo.

Sin embargo, como puntualiza Friedman (2007) con respecto al poder de la Internet, ahora se tiene el desafío de asimilar dichas transformaciones, para lo cual se debe cuidar no abrumar a las personas y tampoco rezagarlas, responsabilidad que no resulta sencilla. Además, se debe pensar en que antes para conocer las tendencias del diseño editorial alrededor del mundo era necesario obtener un ejemplar impreso de cada país o región, mientras que ahora solo basta con dar un clic sobre la pantalla. Por ello, vale analizar algunas respuestas de los entrevistados:

Internet permite identificar las tendencias en las que va dando vueltas el medio, lo cual influye por completo en la calidad de lo que uno genera en sus trabajos (entrevista 12, egresado).

Tiene mucho peso para conocer la tendencias actuales y poder seguir a figuras destacadas del mismo y estar al día de las estrategias nuevas de diseño (entrevista 3, estudiante).

Nos permite investigar sobre el mercado, los consumidores, estrategias para sacarle mayor partido a lo que hacemos, datos que nos aportan mayor conocimiento y más. Todo esto influye directamente al momento de diseñar (entrevista 10, egresada).

Internet provee un feedback casi inmediato a qué tan efectivo es tu diseño, sin este margen de prueba, uno puede irse con la idea de que su diseño será efectivo cuando no lo es (entrevista 2, estudiante). 


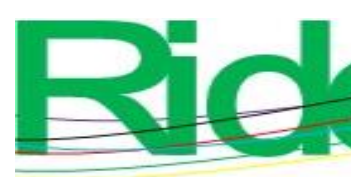

Revista Iberoamericana para la

Investigación y el Desarrollo Educativo

ISSN $2007-7467$

Como se puede apreciar en los comentarios anteriores, la posibilidad de tener proyectos y estilos de diseño en Internet permiten enriquecer el imaginario del diseñador gráfico; sin embargo, vale destacar que estas opciones virtuales no pueden sustituir del todo a las experiencias vivenciales que solo se consiguen, por ejemplo, recorriendo las calles de Barcelona, contemplando la majestuosa obra de Miguel Ángel en la capilla Sixtina o interactuando en persona con otros diseñadores. Esto quiere decir que el diseño gráfico como actividad creativa que es - constituye una profesión que debe partir de la experiencia tangible, de ahí que la Internet solo pueda ser concebida como un aliado.

Aunado a esto, se debe saber que las tendencias más actuales que se observan en Internet se suelen basar en conceptos o diseños de tiempos anteriores. De hecho, muchos estilos de la actualidad que definen a las grandes marcas tienen su origen conceptual en ideas muy antiguas, algunas de las cuales incluso se remontan a la Edad Media (Morales y Cabrera, 2017).

En general, los testimonios de los sujetos entrevistados permiten suponer que la Internet es una completa influencia para la calidad de sus diseños, lo cual pudiera resultar contraproducente, pues la capacidad del diseño gráfico se estaría haciendo extremadamente dependiente de ese recurso. Además, y siguiendo esta perspectiva, la labor del diseñador no habría tenido un verdadero impacto sino hasta el arribo de la marea tecnológica que significó la Internet, algo que la evidencia refuta.

La calidad del diseño de las primeras marcas comerciales en la era industrial — de las tendencias artísticas del siglo XIX y XX, de gran influencia en el diseño actual- son una realidad completamente ajena e independiente a la era de la Internet. La calidad de estos y muchos otros diseños, incluso los de hoy en día, no está condicionada por el apoyo de la Web; prueba de esto es que se puede idear y diseñar para entornos digitales con el apoyo de una simple hoja de papel.

En cambio, lo que ha resultado ser todo un paradigma para el diseño gráfico —así como para otras áreas - han sido las herramientas revolucionarias del feedback (respuestas) que la Internet ha brindado. Gracias a la Red se puede tener retroalimentación instantánea desde cualquier rincón del mundo, lo cual ha ampliado y acelerado las posibilidades. Aun así, no se debe confundir el apoyo de la Internet como herramienta para el perfeccionamiento de un diseño con su completa influencia en la calidad del producto diseñado. 


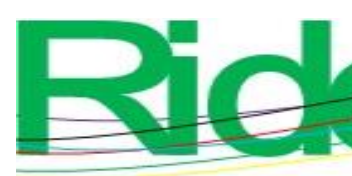

Revista Iberoamericana para la

Investigación y el Desarrollo Educativo

ISSN 2007 - 7467

Por otra parte, y asumiendo que el diseño gráfico es una disciplina que ha enfrentado múltiples cambios ocasionados por el avance de la Web, también se indagó en cómo sería para los entrevistados desempeñar sus tareas sin el apoyo de esta herramienta. Los testimonios de los estudiantes advierten lo siguiente:

Supongo que sin Internet sería un trabajo a ciegas, solo desde mi perspectiva y según mi razonar, lo cual sería incompetente entre los demás colegas (entrevista 18, estudiante).

Imagino que tal vez faltaría un poco ese elemento creativo, o tal vez que el proceso sería menos rápido, porque Internet ayuda mucho en esos aspectos (entrevista 11, estudiante).

Sería terrible. No podría obtener inspiración de ningún lado, buscar lo que no sé, no sabría usar los programas que no me han enseñado o descubrir algunas funciones de esto (entrevista 7, estudiante).

En el imaginario de los estudiantes resulta interesante conocer el valor que dan a la Internet para desempeñar sus labores. Ellos consideran que la Web es una herramienta estrechamente vinculada al diseño, de ahí que alguno de los entrevistados calificara como "terrible" la labor del diseñador gráfico sin Internet.

En estas percepciones no se advierte que el diseño sea un proceso creativo que en otros tiempos se materializaba sin Internet, creación humana que solo tiene algunas décadas de existencia; sin embargo, se debe aceptar que este recurso lo ha fortalecido y ha impulsado el desarrollo del conocimiento de dicho campo. Además, con la Internet el diseño se ha extendido y se ha facilitado el acceso a una infinidad de recursos de todo tipo, lo cual ha favorecido el factor inspiración.

Igualmente, la evidente multidisciplinariedad e interdisciplinariedad que subyace en el diseño gráfico (Morales, 2017) tampoco tiene nada de nuevo, pues desde el pasado más remoto los distintos fenómenos creativos se han interrelacionado en diversos órdenes de manera simultánea (Fragoso, 2011). Por lo anterior, la interdisciplinariedad característica en el diseño de ninguna manera es consecuencia de la Internet.

En este sentido, un grupo de los egresados entrevistados cree que la Internet en realidad tiende a demeritar ciertos aspectos del ejercicio profesional, como se evidencia en testimonios como los siguientes: 


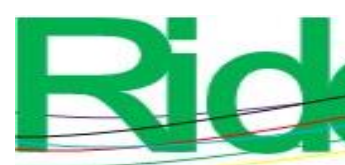

Revista Iberoamericana para la Investigación y el Desarrollo Educativo ISSN $2007-7467$

No creo que sea la pieza clave para que tengan "calidad", simplemente es un apoyo más. Un buen diseñador trata de buscar la mejor forma de solucionar y llegar a obtener un excelente trabajo final. Sin Internet creo que encontraría otras formas de buscar y tener esa calidad..., la inspiración se originaría totalmente desde uno mismo y su alrededor, no se dejaría llevar tanto por todo lo que hay en la Web (entrevista 9, egresado).

Puede que al principio costaría crear desde cero diseños sin Internet e íntegramente solo con lo que tengo, pero con el paso de tiempo terminaría haciendo trabajo de mucho más calidad que en Internet. Es cuestión de ser lo más práctico posible (entrevista 14, egresado).

Tal vez sería más original porque no me vería influenciada por tanta información que hay en Internet (entrevista 8, egresada).

Resulta interesante y asombroso descubrir que los recién egresados tienen otra perspectiva con respecto a la influencia de la Internet en su campo laboral, lo cual es diametralmente opuesto a lo referido por el grupo anterior de estudiantes. Mientras que en el imaginario de los estudiantes conceptualizar el diseño sin Internet resulta desconcertante, los profesionistas — con algunos años en el campo laboral - han concebido la labor de diseñar como un fenómeno integral ajeno a las redes digitales, aunque saben que en algunos casos se pueden complementar.

En concreto, los testimonios dejan entrever que aunque la ausencia de Internet en principio representaría un obstáculo, con el tiempo sus labores no se verían mermadas ni imposibilitadas. De hecho, para alguno de los entrevistados la Internet pudiera convertirse en una "mala influencia" para el proceso de creaciones originales, lo cual en definitiva pudiera ocasionar una paradójica involución. Además, según las opiniones de algunos egresados, la Internet tampoco es la pieza fundamental para conseguir la calidad de las creaciones, aunque sí puede ser considerada como un mecanismo de apoyo para alcanzarla.

Las ideas citadas permiten suponer que el rol que juega la Internet en la experiencia profesional — por corta que esta fuera - influye en el imaginario del diseñador gráfico, así como en su desarrollo, pues están dispuestos a explorar opciones que van más allá de la Web para intentar conseguir productos visuales de calidad, algo que el grupo de estudiantes no contempla. 


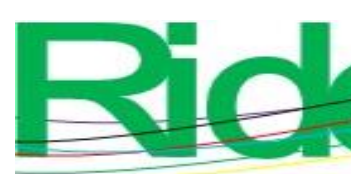

Revista Iberoamericana para la

Por otra parte, en cuanto a las facilidades que brinda la Red para lograr la interconectividad entre las personas, los testimonios recabados fueron los siguientes:

Probablemente los diseños no puedan llegar a tanta gente. Sería más difícil aclarar dudas y no sería posible trabajar fuera de la oficina/estudio (entrevista 10, estudiante).

Quedaría marginado del resto de los diseñadores. Tal vez su trabajo nunca llegue a ser reconocido por el mundo (entrevista 13, estudiante).

Poder comunicarse con rapidez con clientes potenciales, la promoción de su trabajo sería bastante limitada en comparación con la competencia (entrevista 9, egresado).

No podría actualizar mucho su conocimiento sobre los medios digitales, las imágenes, tipografías, entre otras (entrevista 16, egresada).

Efectivamente, Internet abrió un canal de comunicación multidireccional y una realidad a partir de la cual se han podido compartir productos con cualquier persona. En ese sentido, resulta coherente destacar que la Web se ha convertido en la ventana que posibilita la discusión de las creaciones de los diseñadores. De hecho, gracias a la interacción "multidireccional" de Internet, es posible realizar una conversación en tiempo real o escalonada con clientes en cualquier punto geográfico para entrar en una dinámica de retroalimentación, tal como sucede en los foros abiertos u otras plataformas análogas. Esto significa la posibilidad de llevar cualquier producto del diseño gráfico a la vista de millones de personas, con lo cual se puede llegar a trascender y conseguir potenciales clientes. Este es un factor decisivo para promover la competitividad. 


\section{Conclusiones}

Sin duda, el diseño gráfico ha conseguido grandes avances gracias a la Internet; prueba de esto ha sido el continuo surgimiento de nuevos canales de comunicación, plataformas y dispositivos digitales desde los cuales es posible intercambiar ideas con usuarios de cualquier latitud. En este sentido, y con base en la evidencia empírica recabada en este trabajo, se puede sostener que Internet genera un ambiente laboral muy competitivo para el diseño gráfico, pues ahora es posible observar los aportes que en ese campo se realizan en cualquier lugar del mundo, lo cual impacta de forma positiva en los estándares de calidad de los productos creados.

Asimismo, la Red permite explorar las tendencias en tiempo real, así como las técnicas y los estilos mediante distintas plataformas (como Youtube) o cursos en línea que se hallan disponibles las veinticuatro horas del día. Esto permite perfeccionar las técnicas existentes, así como idear otras nuevas, las cuales se pueden perfeccionar interactuando con una mayor cantidad de diseñadores.

Ahora bien, aunque todos estos beneficios son invaluables y no se pueden desvirtuar, también se debe destacar que los estudiantes entrevistados, principalmente, suelen otorgar un peso demasiado importante al apoyo de la Web para sus creaciones artísticas. Incluso, algunos tiendan a concebir a la Internet como la única plataforma capaz de albergar la oferta de diseños y sus tendencias, además de jugar un rol esencial como catalizador y transformador de la creatividad. Esta, sin embargo, es una percepción un tanto errada, pues se olvida que el impulso creativo del ser humano también se ha consolidado incluso en aquellas épocas donde el ciberespacio no existía. En este sentido, los estudiantes opinan que sin la Internet difícilmente se podrían alcanzar diseños de calidad, lo cual es una manera de sobrevalorar a esta herramienta.

Otro aspecto que se debe considerar en el ejercicio del diseño gráfico en los entornos digitales es la ética. Esto significa que si bien la creación gráfica se puede sustentar en las tendencias y en los conceptos visuales hallados en Internet, también se debe procurar conseguir propuestas originales que permitan distinguirse de la competencia.

Por otra parte, y en cuanto a la opinión de los profesionistas entrevistados, se puede señalar que en estos se aprecia una posición más crítica con respecto al uso de la Internet, ya que no la consideran como una pieza clave para la creatividad o para lograr la calidad de un 


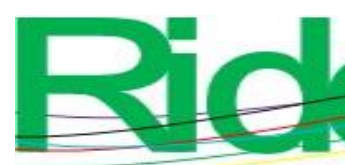

Revista Iberoamericana para la

Investigación y el Desarrollo Educativo

ISSN $2007-7467$

diseño. En pocas palabras, se percibe una interesante disyuntiva conceptual e imaginaria entre estudiantes y profesionistas sobre la interrelación del diseño gráfico y la Internet.

Sin embargo, en otros aspectos sí se hallaron claras convergencias entre ambos grupos, en especial en lo relacionado con la valoración de la Internet como una herramienta que permite no solo exponer y observar los diseños de todo el mundo, sino también retroalimentarse de otras experiencias, trabajar con personas y clientes de otros lugares y capacitarse en innumerables portales.

Todo lo anterior, demuestra la vigente la necesidad de seguir avanzando hacia nuevas formas de enseñar usando la tecnología, pues de ese modo se pueden crear oportunidades para que los estudiantes logren desarrollar sus conocimientos y aplicarlos de forma efectiva en la profesión. En este sentido, y teniendo presentes las tendencias de la formación profesional a nivel nacional e internacional en el campo del diseño, se deberá trabajar en la potenciación de conocimientos, habilidades, contenidos y formas de trabajo acordes a las nuevas exigencias del mercado laboral.

Para ello, el profesor debe mantenerse actualizado no solo en cuanto a sus conocimientos teóricos, sino también en lo referente a sus estrategias de enseñanza, las cuales se deben sustentar ineludiblemente en tecnologías vanguardistas que estimulen la creatividad. En esta tarea, lógicamente, las instituciones universitarias también tienen un compromiso muy grande, porque deberán promover el desarrollo profesional de los docentes, estableciendo y siguiendo programas de capacitación según las necesidades del mercado laboral y las tendencias globales.

Posiblemente, será a través de la innovación en la enseñanza universitaria que se facilite la generación de oportunidades que promuevan significativamente la transformación del ejercicio del diseño, aunque preservando los pilares fundamentales de la profesión, los cuales hacen referencia a un proceso de comunicación visual mediante ideas y conceptos que buscan alcanzar un fin particular dentro de un mercado específico.

Las tendencias que definen la disciplina del diseño gráfico — como otras áreas del diseño - apuntan de manera irrefutable a la tecnología digital. La evolución que experimenta el diseño gráfico se genera a un ritmo vertiginoso, con canales cada vez más novedosos que ofrecen mayores escenarios para desenvolverse. En síntesis, se puede concluir que la comunicación humana de la actualidad se basa — como quizás en ningún momento de la 


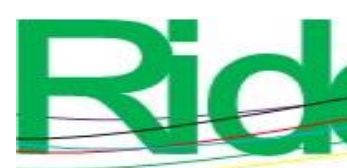

Revista Iberoamericana para la

Investigación y el Desarrollo Educativo

ISSN 2007 - 7467

historia - principalmente en el uso de la imagen y las redes, lo cual ha sido consecuencia directa del uso masivo de la Internet.

\section{Referencias}

Barrientos, P. (2017). Marketing + internet = e-commerce: oportunidades y desafíos. Revista Finanzas y Política Económica, 9(1), 41-56. Recuperado de http://www.redalyc.org/pdf/3235/323549941003.pdf.

Bernal, J. (2013). El diseño gráfico: ¿contribución al consumismo? Revista Legado de Arquitectura y Diseño, (14), 29-40. Recuperado de http://www.redalyc.org/pdf/4779/477947373003.pdf.

Brunner, J. (2003). La educación al encuentro de las nuevas tecnologías. En Brunner, J. J. y Tadesco, J. (eds.), Las nuevas tecnologías y el futuro de la educación (pp. 15-67). Buenos Aires, Argentina: IIPE / UNESCO. Recuperado de http://unesdoc.unesco.org/images/0014/001423/142329so.pdf.

Carpio, I. (2016). Hacia los nuevos campos del diseñador gráfico como especialización de postgrado. Tsantsa. Revista de Investigaciones Artísticas, (4), 1-10. Recuperado de https://publicaciones.ucuenca.edu.ec/ojs/index.php/tsantsa/article/view/1069/941.

Castells, M. (2009). Comunicación y poder. Madrid, España: Alianza Editorial.

Costa, J. (2004). La imagen de marca: un fenómeno social. Ciudad de México, México: Paidós.

Costa, J. (2014). Diseño de comunicación visual: el nuevo paradigma. Gráfica, 2(4), 89-107. Doi:10.5565/rev/grafica.23

Fragoso, O. (2011). La imagen del diseño: el laberinto complejo de la transdisciplina. Revista del Centro de Investigación, 9(35), 35-42. Recuperado de http://www.redalyc.org/articulo.oa?id=34218346005.

Frascara, J. (2000). Diseño gráfico y comunicación. Buenos Aires, Argentina: Infinitobiblioteca del diseño y artes visuales. 


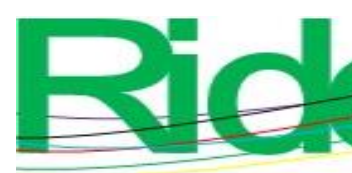

Revista Iberoamericana para la

Investigación y el Desarrollo Educativo

ISSN $2007-7467$

Friedman, T. (2007). La tierra es plana, breve historia del mundo globalizado del siglo XXI. Madrid, España: M. R. Ediciones.

Guerrero, M., Hernandis, B. y Agudo, B. (2018). Aproximación a la representación de la forma y apariencia del producto: estudio sobre los atributos de diseño. Innovar, 28(67), 25-39. Recuperado de https://dx.doi.org/10.15446/innovar.v28n67.68611.

Held, D. and Mcgrew, A. (2007). Globalization Theory, Approaches and Controversies. Londres, Inglaterra: Polity Press.

Husted, S., Álvarez, M., Rodríguez, G., Rodríguez, C. y Mancillas, T. (2016). Tecnologías emergentes: proyecto DigitLAB en el ámbito del diseño gráfico. Revista Iberoamericana de Producción Académica y Gestión Educativa, 3(6), 1-23. Recuperado de http://www.pag.org.mx/index.php/PAG/article/viewFile/458/497.

Jódar, J. (2010). La era digital: nuevos medios, nuevos usuarios y nuevos profesionales. Razón y Palabra, 15(71), 1-11. Recuperado de http://www.razonypalabra.org.mx/N/N71/VARIA/29\%20JODAR_REVISADO.pdf.

Maciá, F. (2014). Marketing online 2.0, cómo atraer y fidelizar clientes en internet. Madrid, España: Anaya Editorial.

Marradi, A., Achenti, N. y Piovani, J. I. (2010). Metodología de las ciencias sociales. Buenos Aires, Argentina: Cengage Learning.

Meggs, P. (2000). Historia del diseño gráfico. Ciudad de México, México: Mc Graw-Hill.

Morales, A. (2017). Complejidad, clave en la transición del diseño gráfico de la práctica profesional a la disciplina intelectual. Taller Servicio 24 horas, 13(25), 15-26.

Morales, A. y Cabrera, V. (2017). Debate teórico-metodológico sobre diseño gráfico: de la linealidad a la complejidad. Intersticios Sociales, (13), 1-28. Recuperado de http://www.redalyc.org/articulo.oa?id=421749924002.

Ohmae, K. (2005). El próximo escenario global, desafíos y oportunidades en un mundo sin fronteras. Madrid, España: McGraw-Hill.

Puddephatt, A. (2016). Internet y la libertad de expresión. Montevideo: UNESCO. Recuperado de http://unesdoc.unesco.org/images/0024/002466/246670S.pdf. 
Rand, P. (1965). Design and the Play Instinct. Education of Vision. Retrieved from https://alexanderwwhite.files.wordpress.com/2015/08/designandplayinstinctpaulrand.pdf.

Sánchez, M. (2009). La revolución digital en el diseño gráfico. Actas de diseño, 7(4), 255257.

http://fido.palermo.edu/servicios_dyc/publicacionesdc/archivos/16_libro.pdf

Velásquez, A. y Paladines, F. (2011). Uso de otras formas de comunicación. Consumo de medios en los estudiantes universitarios. Análisis de Internet y teléfono móvil-Caso UTPL. Razón y Palabra, (77), 1-24. Recuperado de http://www.razonypalabra.org.mx/varia/77\%205a\%20parte/74_VelasquezPaladines_V7 7.pdf.

\begin{tabular}{|l|l|}
\hline Rol de Contribución & Autor (es) \\
\hline Conceptualización & Edgar Oswaldo González Bello y Arodi Morales Holguín «igual» \\
\hline Metodología & Edgar Oswaldo González Bello \\
\hline Software & Edgar Oswaldo González Bello \\
\hline Validación & Edgar Oswaldo González Bello \\
\hline Análisis Formal & Edgar Oswaldo González Bello \\
\hline Investigación & Edgar Oswaldo González Bello y Arodi Morales Holguín «igual» \\
\hline Recursos & Edgar Oswaldo González Bello y Arodi Morales Holguín «que apoya». \\
\hline Curación de datos & Edgar Oswaldo González Bello \\
\hline Escritura - Preparación del & Edgar Oswaldo González Bello y Arodi Morales Holguín «igual» \\
\hline borrador original & \\
\hline Visualización & Edgar Oswaldo González Bello y Arodi Morales Holguín «igual» \\
\hline Supervisión & Edgar Oswaldo González Bello y Arodi Morales Holguín «igual» \\
\hline Administración de Proyectos & Edgar Oswaldo González Bello \\
\hline Adquisición de fondos & Edgar Oswaldo González Bello y Arodi Morales Holguín «igual» \\
\hline
\end{tabular}

